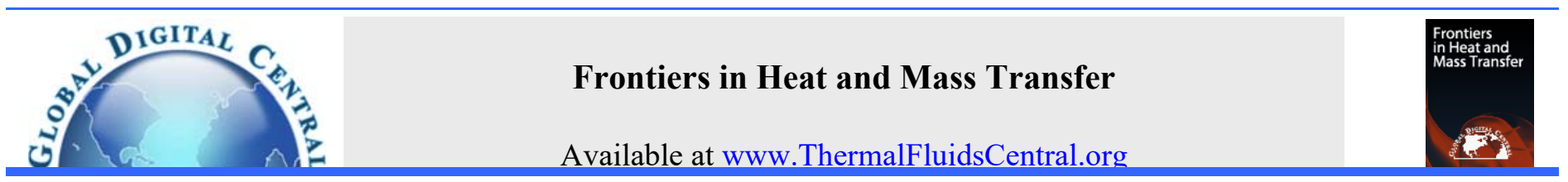

\title{
EXPERIMENTAL COOLER BOX PERFORMANCE USING TWO DIFFERENT HEAT REMOVAL UNITS: A HEAT SINK FIN-FAN, AND A DOUBLE FAN HEAT PIPE
}

\author{
Mirmanto*, I.B. Alit, I.M.A. Sayoga, R. Sutanto, Nurchayati, A. Mulyanto \\ Mechanical Engineering Department, Engineering Faculty, Mataram University, Mataram, NTB, 83125, Indonesia \\ Jl. Majapahit no. 62, Mataram, NTB, 83125, Indonesia
}

\begin{abstract}
A comparison study of the use of two different heat removal units was conducted to examine the performance of thermoelectric cooler box. The heat removal units employed were a heat sink fin-fan and a double fan heat pipe. Parameters measured as performance indicators are cooling capacity, temperature differences, and COP. In addition, the effect of electrical power on temperature difference and COP was also investigated. The cooler box size is $285 \mathrm{~mm}$ x $245 \mathrm{~mm}$ x $200 \mathrm{~mm}$ and constructed from styrofoam. The results show that there is no difference of the use of a double fan heat pipe or a heat sink fin-fan on the cooler box performances. The Carnot COP decreases with the time, while the experimental COP increases with the time then it is constant after the steady condition has been achieved. Increasing the power decreases the COP but increases the temperature difference.

Keywords: Cooler box, Thermoelectric, Heat removal unit, COP
\end{abstract}

\section{INTRODUCTION}

A portable medical refrigerator is essential to carry out planned immunization, preventive injection, serum and biological preparations. Over the past years until nowadays, a small box filled with ice is commonly used for transporting/ storing fish by fishermen. Foam cotton, ice bottle, glass liner are also used as insulation materials to prevent the heat coming into/ out the storage box. Ice cream sellers using a motorbike also use styrofoam boxes filled with an ice stone to avert their ice cream melting. This manner is not easy and effective. Also, using cotton, foam and other materials to make the box at a constant temperature causes the package to be large, small volume, and high cost, etc. (Yang et al., 1991). Therefore, there is an urgent demand for such works to find a new cooler box that is portable, small power, and temperature-controlled.

To fulfil the demand, a thermoelectric cooler (TEC) box is a better choice. TEC is a new artificial refrigeration technology which is based on the Peltier effect. The cold side of the thermoelectric can be used for absorbing heat or cooling things, Abdul-Wahab et al. (2009), Rawat et al. (2013), Reddy (2016), Ananta et al. (2017). Recently, studies on TEC have been quickly developed. Although the efficiency of TEC is lower compared with traditional refrigeration, it is irreplaceable for some cases. TEC is quiet, portable, and environmentally friendly and it has a high temperature-controlling capacity, Deng (1992). Furthermore, the advantages of TEC are no leakage problem, very compact, durable, easy in maintenance, and low power, Andersen (1962), Mei et al. (1989), McNaughton et al. (1995). Hence, it is suitable to be applied to the medical field or other purposes as mentioned in the previous paragraph.

Most previous work on TEC system has examined optimization and performance improvement of electronic devices by building various thermoelectric modules, Shen et al. (2013), Cai et al. (2016), Cai et al. (2017), Chen et al. (2015), Lineykin and Ben-Yaakov (2007),
Manikandan and Kaushik (2015). However, increasing the performance of the cooler box is difficult due to low COP (coefficient of performance) of the thermoelectric module (TE). Some researchers tried to increase the performance of TE by discovering new materials, e.g. Ghoshal et al. (2002), Yang et al. (1991) and Lee et al. (2015). Nevertheless, what they did does not improve the performance much. Then $\mathrm{Lu}$ et al. (2014) enhanced their TE refrigeration system by applying inhomogeneous thermal conductivity materials. They elucidated that this method increased the performance of the cooling system. Moreover, Rabari et al. (2015) investigated the effect of a thermal conductivity on the performance of TE systems. They concluded that this way increased the COP. Attey (1998) increased the COP in applications. They revealed that using low thermal impedance liquid raised the COP surprisingly, and even when they applied a solid heat sink, the COP obtained was approximately ranging from $0.4-0.6$, but when they utilized liquid as the heat sink, the COP leveled by of approximately $0.95-1.85$. Recently Reddy et al. (2013) also performed an investigation to increase the COP of their thermoelectric cooling system. They found a significant increase in COP or performance. Yu and Wang (2009) improved TE cooling system using internally cascaded TE couples and they found the significant increase in COP. Nevertheless, most of them found that COP of TEC was still lower than 1 , see also Table 1 .

From the above literature or Table 1, several types of heat sink installed on the hot side of TE to remove the heat have been investigated. Nevertheless, none of them investigated the effect of the use of different heat sinks (outer heat sinks) on the cooler box performance. Meanwhile, different heat sinks have different capacity to remove heat from the hot side of TE. Although the power used to operate the cooler box is the same, but different heat sinks employed may result in different performances. Therefore, this study investigates the effect of two different outer heat sinks on the cooler box performance.

\footnotetext{
*Corresponding Author Email: m.mirmanto@unram.ac.id
} 
Table 1 COP reported in the literature

\begin{tabular}{|l|l|l|l|l|l|l|}
\hline Ref. & $\begin{array}{l}\text { Volume } \\
\left(\mathrm{m}^{3}\right)\end{array}$ & $\begin{array}{l}\Delta T=T_{H}- \\
T_{C}\left({ }^{\circ} \mathrm{C}\right)\end{array}$ & $\begin{array}{l}\text { Module power (W)- } \\
\text { number }\end{array}$ & COP & Hot side system & Cold side system \\
\hline $\begin{array}{l}\text { Abdul-Wahab et al. } \\
(2009)\end{array}$ & 0.013 & 22 & $9.5-10$ & 0.16 & $\begin{array}{l}\text { Air heat sink fan, } \\
\text { forced flow }\end{array}$ & $\begin{array}{l}\text { Air heat sink fan, forced } \\
\text { flow }\end{array}$ \\
\hline Ananta et al. (2017) & 0.033 & 18.6 & $12-2$ & 0.33 & Air heat sink fan & Heat sink natural flow \\
\hline $\begin{array}{l}\text { Vian and Astrain } \\
(2008)\end{array}$ & 0.225 & 11.2 & $50-1$ & 0.39 & $\begin{array}{l}\text { Phase change } \\
\text { Thermosypon }\end{array}$ & Thermosypon porous media \\
\hline & 0.225 & 14.67 & $50-1$ & 0.29 & $\begin{array}{l}\text { Phase change } \\
\text { Thermosypon }\end{array}$ & Finned heat sink \\
\hline $\begin{array}{l}\text { Min and Rowe } \\
(2006)\end{array}$ & 0.115 & 10 & $52-1$ & $0.3-0.5$ & Liquid heat exchanger & Finned heat sink \\
\cline { 2 - 7 } & 0.04 & 16 & $120-1$ & 0.2 & Liquid heat exchanger & Liquid heat exchanger \\
\hline $\begin{array}{l}\text { Jugsujinda et al. } \\
(2011)\end{array}$ & $8.3 \times 10^{-5}$ & 17.6 & - & 0.1 & Air flow & Planar heat pipe \\
\hline $\begin{array}{l}\text { Tan and Zhao } \\
(2015)\end{array}$ & 0.225 & 18.9 & $50-2$ & & $\begin{array}{l}\text { Thermosypon with } \\
\text { two phase }\end{array}$ & $\begin{array}{l}\text { Thermosypon with two } \\
\text { phase and capillary lift and } \\
\text { cold extender }\end{array}$ \\
\hline
\end{tabular}

\section{RESEARCH METHOD}

\subsection{Experimental Facility and Method}

The schematic diagram of the cooler box system is shown in Fig. 1. At the beginning of the experiment, all temperatures were the same as the ambient temperature. For simplifying the cooler box model, the cooler box was made of styrofoam materials. Such cooler box is usually used by fishermen when they are fishing. However, this box can also be utilized for cooling drinking water or soft drink or even ice creams.

Table 2 Specifications of heat sink fin-fan and double fan heat pipe

\begin{tabular}{|l|l|}
\hline $\begin{array}{l}\text { Double fan heat pipe } \\
\text { Fan Speed: }\end{array}$ & $800-1600 \pm 10 \% \mathrm{RPM}$ \\
\hline Voltage & $12.13 \mathrm{~V}$ (measured) \\
\hline Current & $0.69 \mathrm{~A}$ (measured) \\
\hline Fan Dimension: & $120 \mathrm{X} 120 \mathrm{x} 25 \mathrm{~mm}$ \\
\hline Bearing type: & Hydraulic \\
\hline Feature: & LED light cooling fan \\
\hline Rated Power: & DC 12V 0.69A \\
\hline Power Connection: & $3-\mathrm{Pin}$ \\
\hline Heat sink fin-fan & Ball \\
\hline Bearing Type: & Intel \\
\hline Brand: & C28085-001 \\
\hline MPN: & $12 \mathrm{~V}, 0.13 \mathrm{~A}$ \\
\hline Rated voltage and current &
\end{tabular}

All temperatures were measured using calibrated K-type thermocouples with an uncertainty of $\pm 0.5^{\circ} \mathrm{C}$. While the power flowed to the thermoelectric was measured using a multimeter (model Professional Vichy Vc8145 Dmm Digital Bench Top Multimeter), see Fig. 2(d). The thermoelectric used was double plate thermoelectric (model TEC2-25408) as shown in Fig. 2(c). The material of the thermoelectric is ceramic (both surface), the semiconductor material (between two ceramic plates). The dimension of TE is $40 \mathrm{~mm}$ x $40 \mathrm{~mm}$ x $6.0 \mathrm{~mm}$, and the TE contains 190 stacks of the P-N semiconductor junction. The rated voltage, current and power are 12-15.2 V, $8 \mathrm{~A}$, and $65 \mathrm{~W}$ respectively. The maximum temperature difference is $80^{\circ} \mathrm{C}$.
Meanwhile, the two types of the outer heat sink were heat sink fin-fan and double fan heat pipe, as shown in Fig. 2(a) and (b), and their specifications are shown in Table 2. The size of the cooler box was approximately of $285 \mathrm{~mm} \times 245 \mathrm{~mm} \times 200 \mathrm{~mm}$, while the thickness of the box walls was $30 \mathrm{~mm}$. Therefore, the volume of the cooler box is of $0.00489 \mathrm{~m}^{3}$.

Experiments were conducted using two different heat removal units, and the data were analyzed to determine the cooling capacities $\left(Q_{C}\right)$ and the COP. After that, the $Q_{C}$ and COP obtained using heat sink fin-fan unit are compared with those attained using the double fan heat pipe unit. All experiments were conducted under the same conditions. In addition, experiments investigating the effect of the thermoelectric power on the cooler box performances were also performed as additional information in this paper. The power used in this study were ranging from $1.04 \mathrm{~W}$ to $38.76 \mathrm{~W}$, see Table 3.

Table 3 Volt, current and power tested

\begin{tabular}{|l|l|l|}
\hline \multicolumn{2}{|l|}{ Tested power variable: } \\
\hline Heat sink fin-fan & $I$ (Ampere) & Power $(\mathrm{W})$ \\
\hline$V$ (Volt) & 0.54 & 1.04 \\
\hline 1.93 & 1.58 & 8.32 \\
\hline 5.26 & 2.40 & 19.20 \\
\hline 8.00 & 2.68 & 23.68 \\
\hline 8.85 & 2.95 & 38.76 \\
\hline 10.86 & \multicolumn{2}{|l|}{} \\
\hline Double fan heat pipe & $I($ Ampere $)$ & Power $(\mathrm{W})$ \\
\hline$V($ Volt $)$ & 0.55 & 1.05 \\
\hline 1.90 & 1.74 & 9.90 \\
\hline 5.70 & 2.40 & 18.83 \\
\hline 7.84 & 2.74 & 24.42 \\
\hline 8.92 & 3.12 & 36.05 \\
\hline 10.22 &
\end{tabular}

\subsection{Heat Transfer Analysis}

In this study, some equations are used to estimate the cooling capacity such as heat from the air inside the cooler box, heat conduction through the cooler box walls, COP. To estimate the air heat absorbed by the inner heat sink, an equation taken from Cengel (2003) can be utilized. This equation was also used by Ananta et al. (2017), Gokcek and Sahin (2017). Actually, this equation is an equation to predict the heat from the product in the refrigerator or cooler box. In this study, inside the cooler box is only air, therefore, the air represents the product owing mass and 
specific heat. The properties of the air at the atmospheric pressure can be seen in Cengel (2003).

$Q=\frac{d E}{d t}=\frac{d\left({ }^{c}{ }_{p} T\right)}{d t}=\frac{m_{(i)}{ }^{c} p(i) T_{(i)}-m_{(i-1)}{ }^{c} p(i-1) T_{(i-1)}}{t_{(i)}-t_{(i-1)}}$

Where $Q$ is the heat transfer rate from the air (product) inside the cooler box (W), $m$ is the product mass $(\mathrm{kg}), c_{p}$ is the specific heat of the air (product) $\left(\mathrm{J} / \mathrm{kg}^{\circ} \mathrm{C}\right), T$ is the air temperature that is equal to the average temperature of the cooler box space $\left({ }^{\circ} \mathrm{C}\right)$, and $t$ is the time during the cooler box is operated (s).

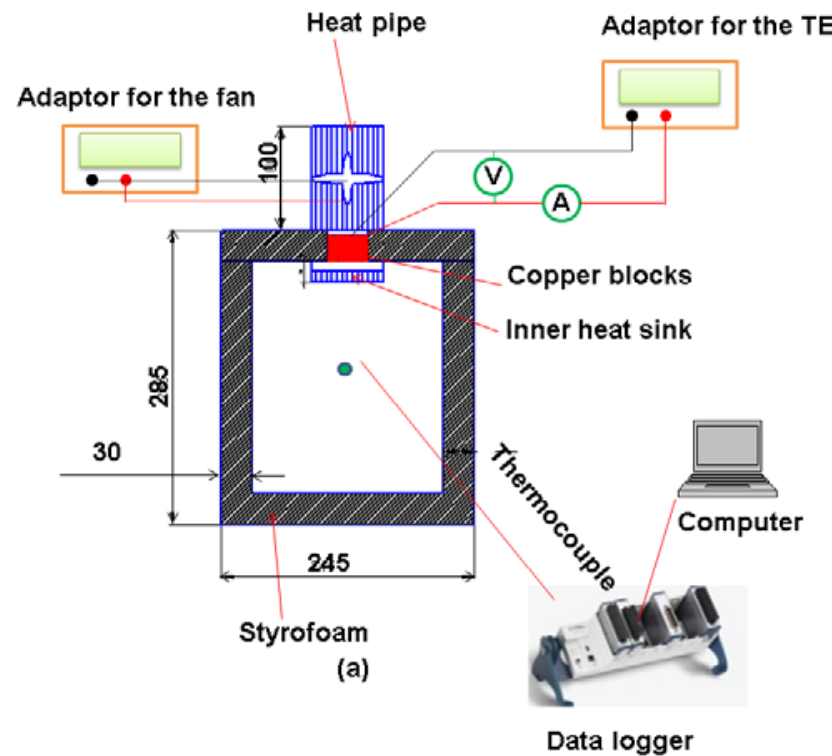

Electrical circuit

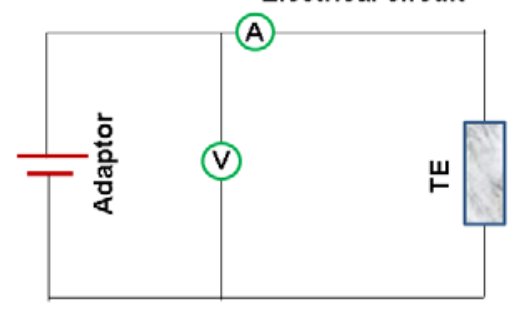

(b)

Fig. 1 Schematic diagram of the experimental facility; (a) cooler box, (b) electrical circuit diagram, (c) the photograph of the test rig. Figure dimension is in mm but without scaling. TE (thermoelectric module).

$Q_{k}=\frac{d E}{d t}=\frac{d\left(-k A \frac{d T}{d x} d t\right)}{d t}=\frac{-k A d T}{d x}=\frac{k A\left(T_{o(i)}-T_{i n(i)}\right)}{\Delta x}$

The heat transfer area, the wall thickness, and the thermal conductivity do not change with the time. $T_{\text {in }}$ is the inner wall temperature $\left({ }^{\circ} \mathrm{C}\right), T_{o}$ is the outer wall temperature $\left({ }^{\circ} \mathrm{C}\right)$ Then the power supplied to the thermoelectric, $P_{i n}$, is evaluated as

$P_{i n}=V I$

Where $P_{\text {in }}$ is the power supplied to the thermoelectric (W), $V$ is the voltage $(\mathrm{V})$, and $I$ is the current $(\mathrm{A})$. The cooling capacity is determined using Eq. (4). Eqs. (3) and (4) were also utilized in some papers to calculate the power and the COP, e.g. Abdul-Wahab et al. (2009), Ananta et al. (2017), Cai et al. (2016), Wang et al. (2017).

$Q_{c}=Q+Q_{k}$

Then, the experimental coefficient of performance of the cooler box can be expressed as:

$$
C O P=\frac{Q_{c}}{P_{i n}}=\frac{Q_{c}}{V I}
$$

Where $Q_{C}$ is the cooling capacity (W) that is equal to the amount of the heat absorbed by the inner heat sink and flowed toward the cold side of the thermoelectric.

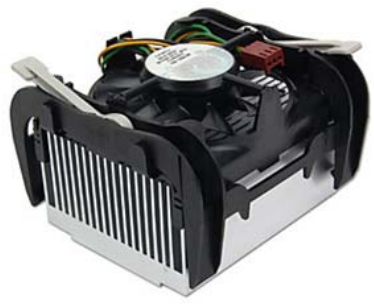

(a)

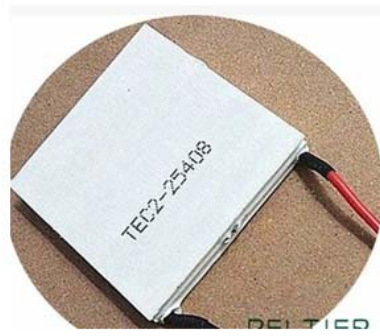

(c)

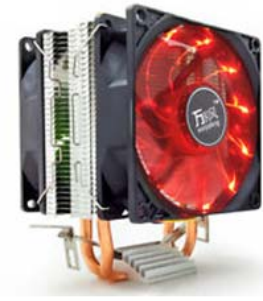

(b)

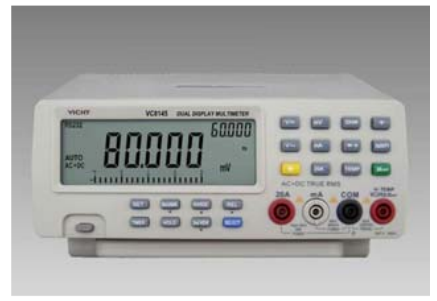

(d)
Fig. 2 Heat sink; (a) heat sink fin-fan, (b) double fan heat pipe, (c) thermoelectric and (d) multimeter.

\section{RESULTS AND DISCUSSION}

\subsection{Temperatures and $\Delta T$}

This current study was intended to investigate the different performance of the thermoelectric cooler box using two different heat removal units. However, the important things indicating the thermoelectric cooler box performances are the cooler box temperature and coefficient of performance (COP). Cooler box temperatures were measured for about 10000 s so that the transient trends of the temperature could be seen entirety, see figure 3 . In general, figure 3 shows that increasing the power decreases the room temperatures. At the power of about $1 \mathrm{~W}$, the room temperature that can be reached is around $18^{\circ} \mathrm{C}$ for the heat sink and fan (HSF), or $16^{\circ} \mathrm{C}$ for the double fan heat pipe (DFHP). All temperatures decrease with increasing observation time as also found by Totala et al. (2014), Tan and Zhao (2015), Ananta et al. (2017). Using DFHP, the cooler box has lower temperatures at the same power, however, figure 3 may not be able to be used for making a conclusion about the use of HSF or DFHP. The reason is that the room temperature resulted depends on the hot side temperature as well. Higher hot side temperatures at the same given power may elevate the room temperature and vice versa. Therefore, using temperature differences to assess the performance of the cooler box employing HSF and DFHP is more convenient. 

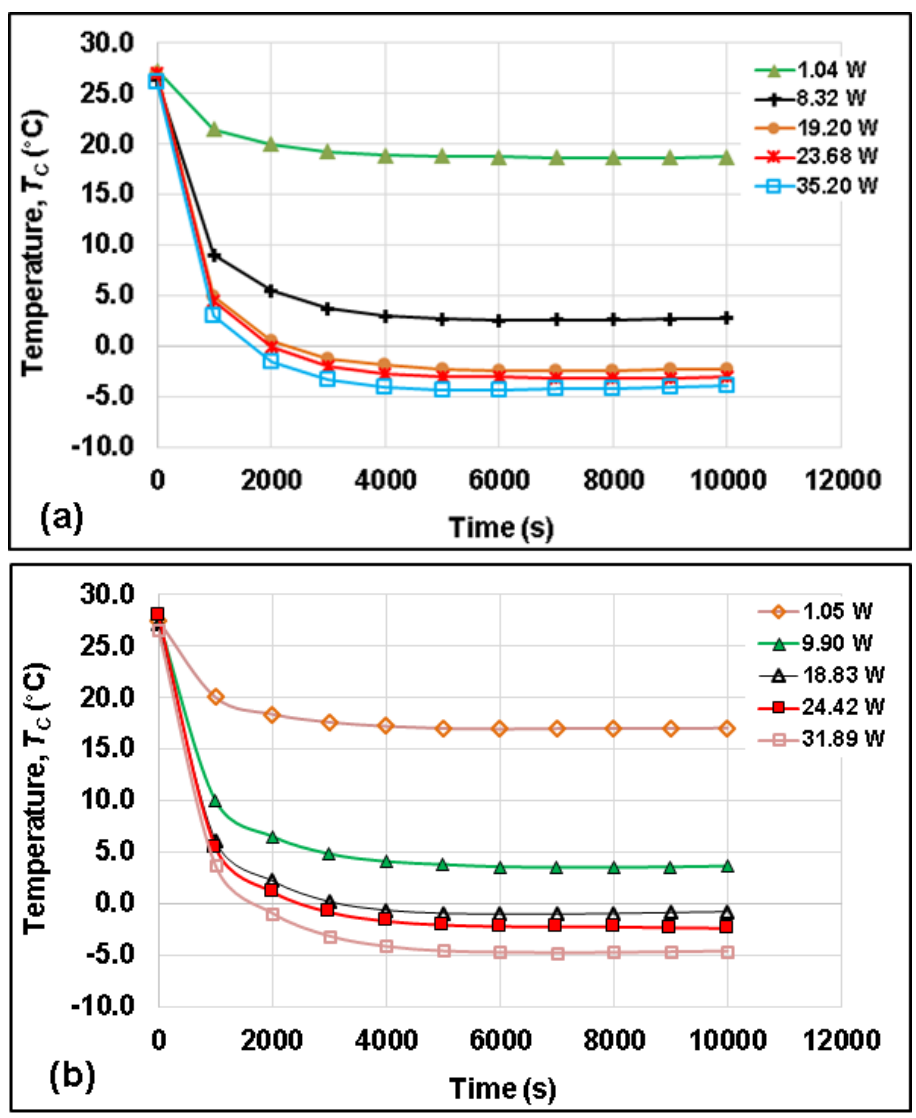

Fig. 3 Room temperatures at several powers; (a) heat sink and fan heat removal unit (HSF), (b) double fan heat pipe (heat removal unit DFHP).

From Fig. 4, it can be seen that at the same given power, using HSF results in higher $\Delta T$. Meanwhile, based on the theory of thermoelectric, see Eq. (5), higher $\Delta T$ at the same power reduces the cooling capacity of the TE. http://www.ferrotec- nord.com/support /choosingthermoelectric-modules.

$Q_{C}=Q_{C \max }\left(\Delta T_{\max }-\Delta T\right) / \Delta T_{\max }$

Where $Q_{\mathrm{cmax}}$ is the maximum cooling capacity (W) and $\Delta T_{\max }$ is the maximum temperature difference $\left({ }^{\circ} \mathrm{C}\right)$. The maximum cooling capacity is $65(\mathrm{~W})$ and the maximum temperature difference is $80^{\circ} \mathrm{C}$.

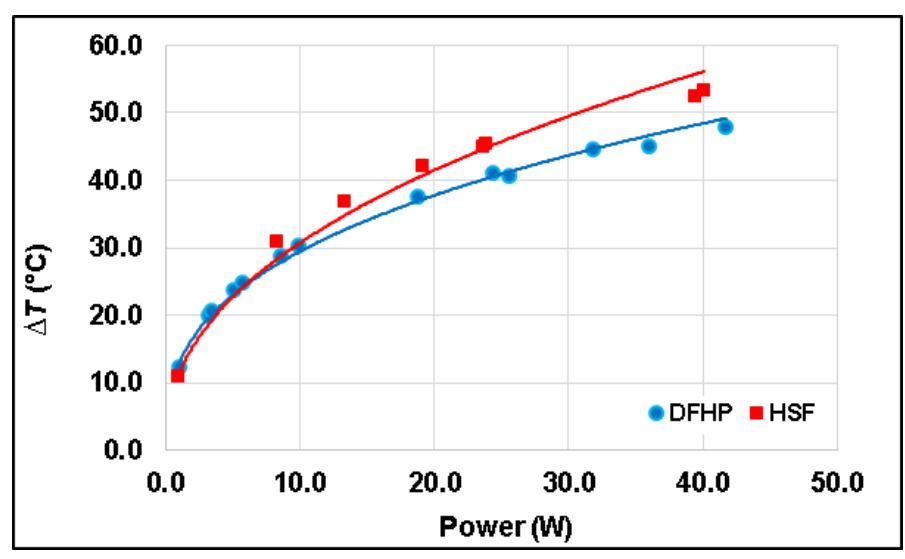

Fig. 4 Effect of power on $\Delta T$ for both DFHP and HSF

\subsection{Heat Transfer Rate}

Heat transfer rate in this study comprises (i) heat transfer rate from the air inside the cooler box, (ii) heat transfer rate from conduction heat transfer flowing from the ambient to the cooler box room through the cooler box walls. The last heat transfer rate is seldom presented in the literature of cooling system using thermoelectric. Therefore, this is becoming the focus of this current study. To calculate the heat transfer rate from the air, Eq. (1) can be used. The results are shown in Fig. 5.
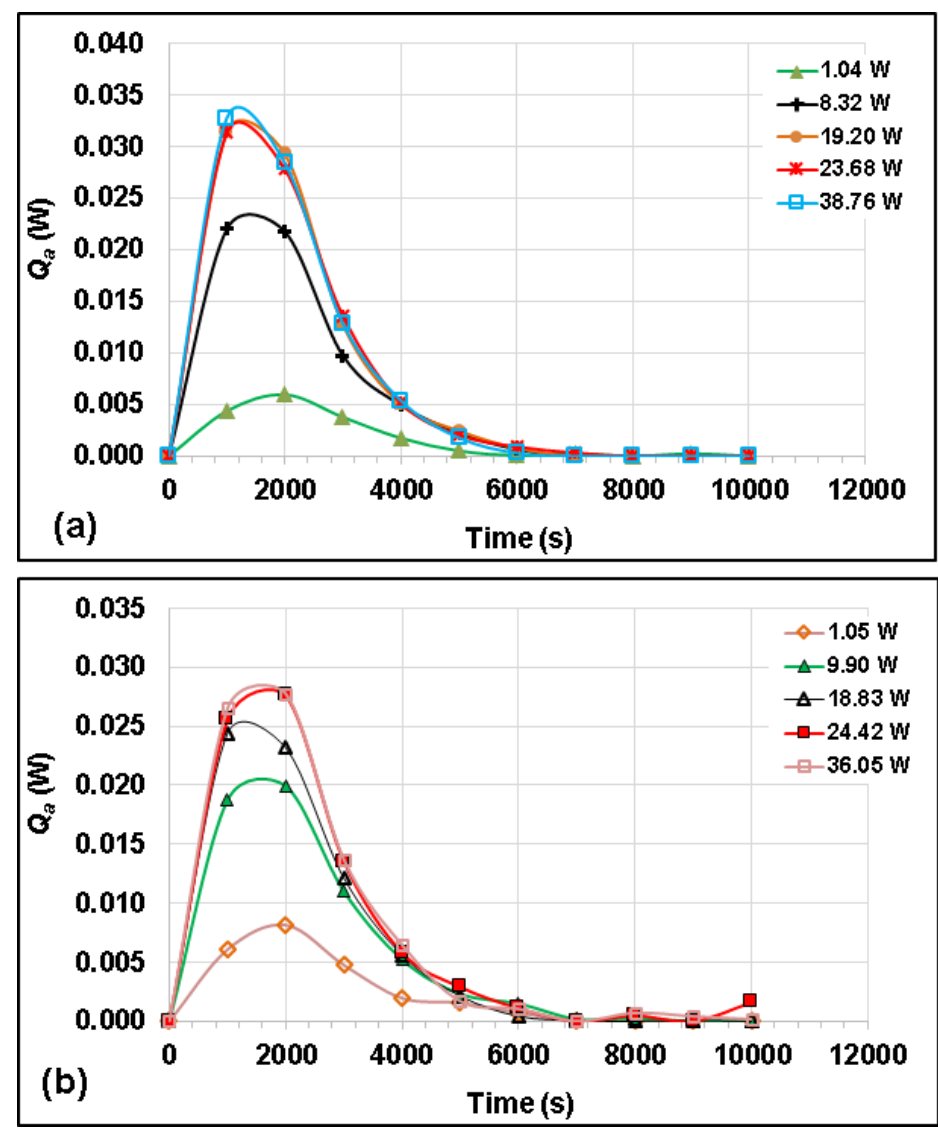

Fig. 5 Heat transfer rate from the air versus observation time; (a) HSF; (b) DFHP

In Fig. 5, heat transfer rate from the air at all powers decreases with the time but increases with the power. The decreased heat transfer rate is due to the cooler box room temperatures. The cooler box room temperatures decrease with the time and even become constant after steady conditions have been reached. At the steady condition, the heat transfer rate from the air is zero, however, the conduction heat transfer becomes dominant. The dominant heat transfer is presented in Fig. 6 . Nevertheless, phenomena in Fig. 5 are obvious due to Eq. (1), but perhaps none of the above literature presented the phenomena. Therefore, the authors are persuaded to include the phenomena in this paper as a reference for further research in the use of TE for the cooler box. From Fig. 5, it is clear that the peak of the air heat transfer rate for HSF is higher than that of DFHP especially at the time of around $2000 \mathrm{~s}$. However, after that, they both get constant and close to zero.

As presented in Fig. 6, the conduction heat transfer rate has different trend compared with the heat transfer rate from the air. The conduction heat transfer rate increases with the observation time. This is also due to the cooler box room temperatures. The lower cooler box temperature, the higher conduction heat transfer rate prevails. This agrees with Eq. (2). When $T_{i n(\mathrm{i})}$ gets lower while $T_{o(\mathrm{i})}$ remains persistent, then $Q_{k}$ increases. The trends occurring are similar at all given powers. In Fig. 6, there is an opposite phenomenon, the conduction heat transfer rate obtained 
using HSF seems to be higher than that attained using the DFHP. At the power of $38.76 \mathrm{~W}$ for the HSF, the conduction heat transfer rate is approximately of $0.08 \mathrm{~W}$, while that for the DFHP at the power of 36.05 $\mathrm{W}$ is approximately of $0.068 \mathrm{~W}$. Meanwhile, at the lower power, the conduction heat transfer rate for HSF is almost the same as that of DFHP. Further analysis that may be able to give clear information about the use of those two different heat removal units is given in Fig. 7. Fig. 7 presents the total heat transfer rate or the cooling capacity for both HSF and DFHP at several operating powers. Here is clear that the total heat transfer rate for HSF is higher than that for DFHP. However, at the lower power such as around $1 \mathrm{~W}$, the DFHP results in higher $Q_{c}$.
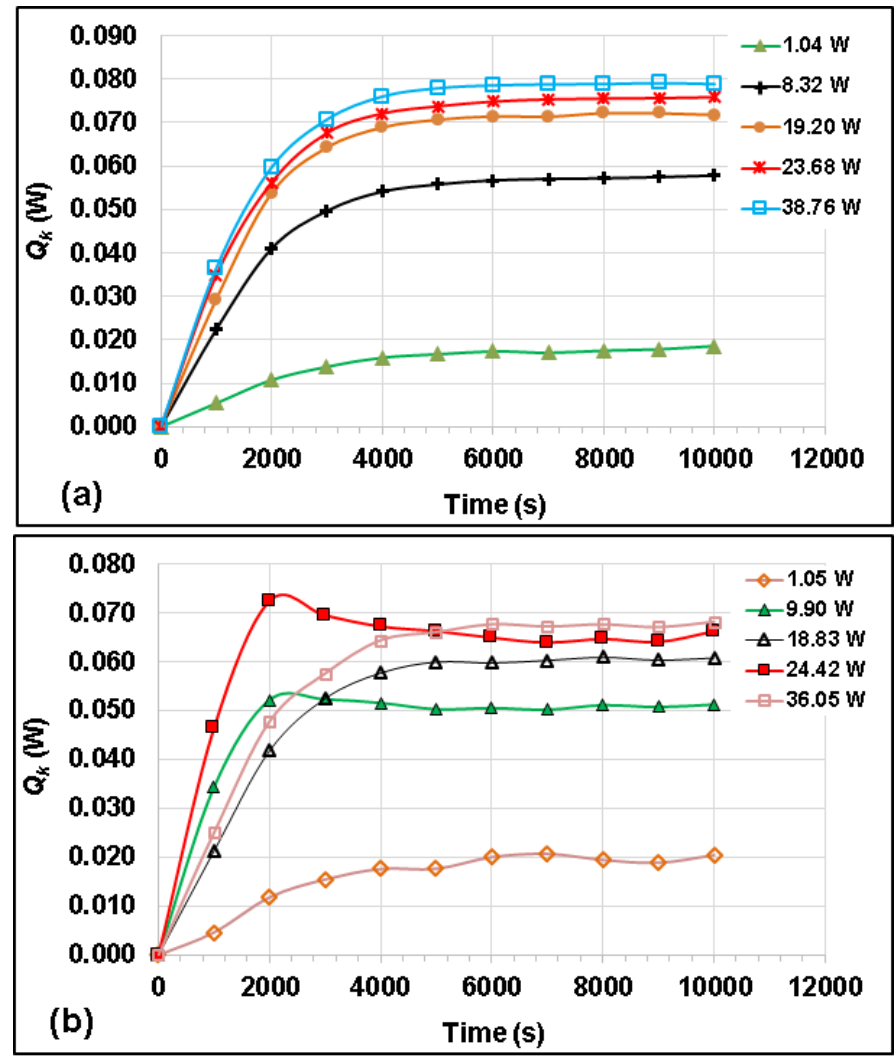

Fig. 6 Conduction heat transfer rate through the cooler box walls; (a) HSF; (b) DFHP

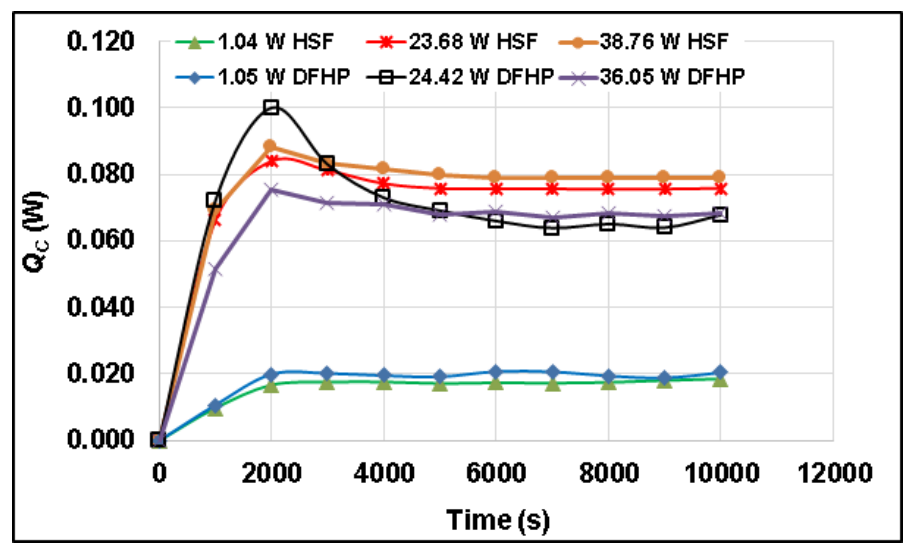

Fig. 7 Total heat transfer rate, Qc, for HSF and DFHP at several powers.

\subsection{Carnot COP and Experimental COP}

Figs. 8 and 9 present COP of the cooler box for both heat removal units. There are two kinds of COP that can be explored in this study. First is COP based on the Carnot refrigeration engine, Fig. 8, and the second is experimental COP based on the cooling capacity calculations, Fig. 9. From Fig. 8, it can be seen that the COP decreases with the time and then it gets constant. The trends are similar for all, even these were also found by Jugsujinda et al. (2011), Gokcek and Sahin (2017). At the lower power, the COP based on the Carnot refrigeration system for HSF is greater than that of DFHP, while at the higher power, the COP is just almost the same for both HSF and DFHP. The Carnot COP is obtained using Eq. (7).

$$
\mathrm{COP}_{c}=\frac{T_{c}}{T_{H}-T_{c}}
$$

Where in Eq. (7) the temperatures are in absolute $(\mathrm{K})$. This equation was used in Jugsujinda et al. (2011), Su et al. (2018). They used Eq. (7) to present their COP rather than experimental COP based on actual cooling capacities. Moreover, they did not present the conduction heat transfer rate.
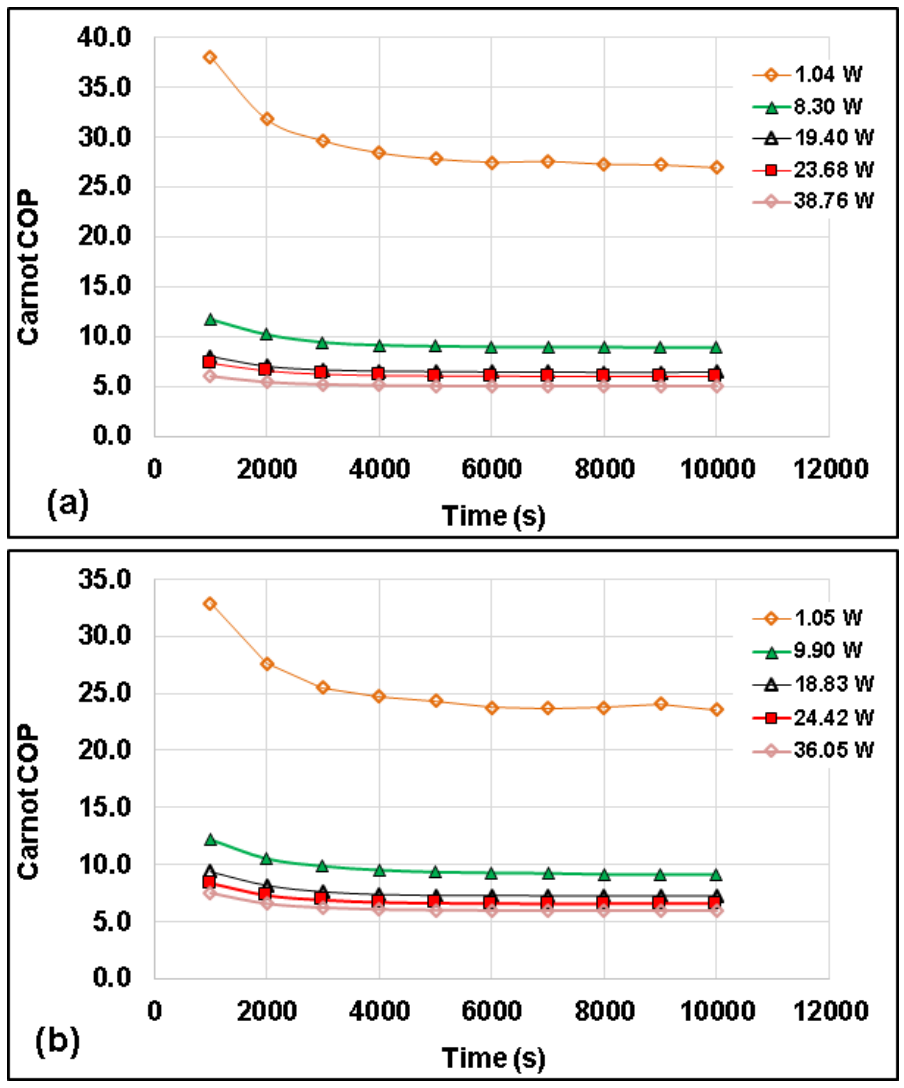

Fig. 8 Relationship between Carnot COP and observation time for: (a) HSF, (b) DFHP

Experimental COP increases with the time after conditions reach steady state, and then it becomes constant. This phenomenon occurs for both HSF and DFHP. In Fig. 9, it can be seen that at the lower power, the experimental COP for DFHP is higher than that of HSF, while at the higher powers, it almost the same. Moreover, at the lower power, Figs. 8 and 9 contradict each other. From the experimental COP, Fig. 9, it can be concluded that using DFHP is better. Considering the fan power used for HSF and DFHP may be important. The HSF uses one fan with a power of $1.56 \mathrm{~W}$, while the DFHP employs a double fan with the power of $8.4 \mathrm{~W}$. Therefore, the use of HSF is more convenient. 


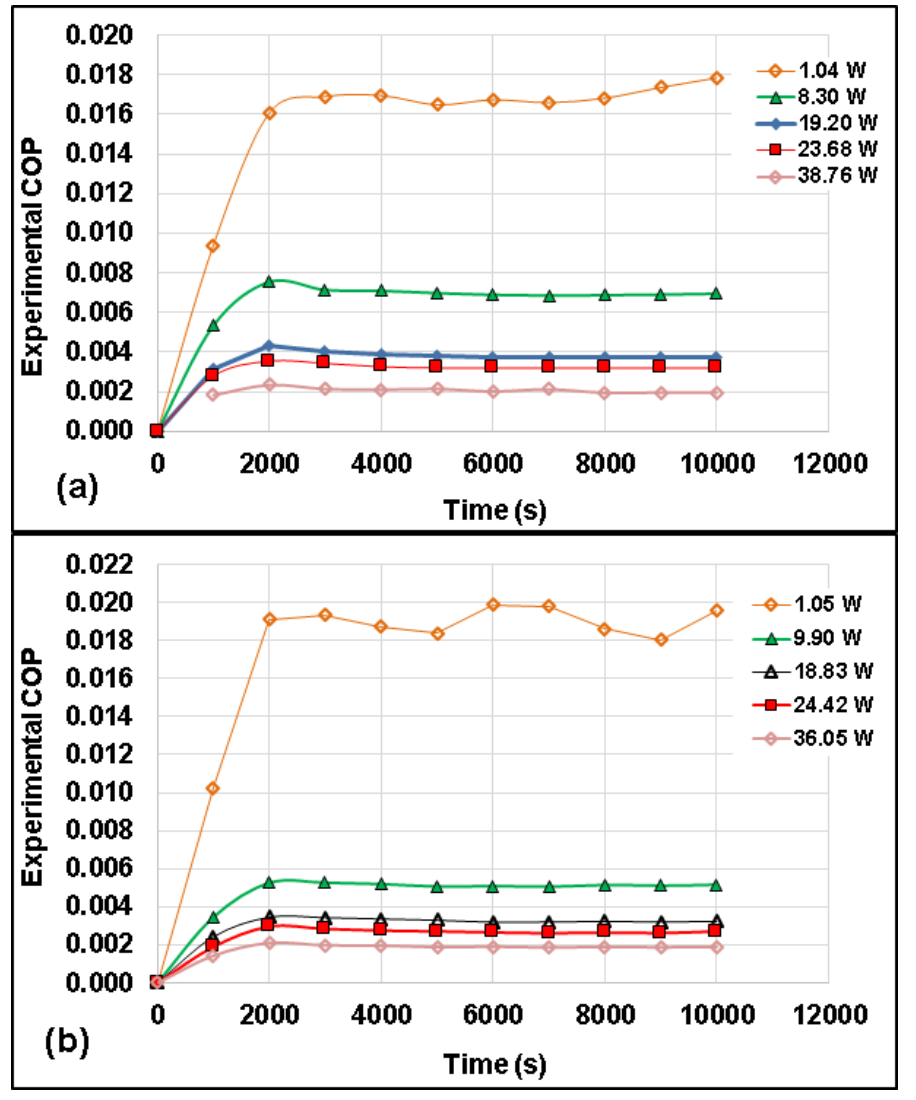

Fig. 9 Relationship between experimental COP and observation time for: (a) HSF, (b) DFHP

\section{CONCLUSION}

Experimental study on the use of two different heat removal units applied to the cooler box has been performed. The comparison of COP resulted in the use of heat sink fin-fan unit and double fan heat pipe unit has been analyzed and discussed. Some conclusion can be drawn as follows:

1. The cooler box temperature decreases with the time.

2. The heat transfer rates from the air decrease with the time.

3. The conduction heat transfer rate increases with the time then after the steady conditions have been achieved, it is constant.

4. The Carnot COP decreases with the time, and then after a steady condition occurs it becomes constant.

5. The experimental COP increases with the time, and then it is constant after it has been steady.

6. The effect of the heat removal unit is not clear, but when the energy consumed by the unit is considered, the heat sink finfan is more reliable.

\section{ACKNOWLEDGMENTS}

The authors would like to acknowledge the Mechanical Engineering Department for the facility, and thank everybody who has helped in writing this paper.

\section{NOMENCLATURE}

$A \quad$ heat transfer area $\left(\mathrm{m}^{2}\right)$

$c_{p} \quad$ specific heat $(\mathrm{J} / \mathrm{kg} \mathrm{K})$

$d E \quad$ the change of energy (J)

$d t \quad$ the change of time (s)

$d x \quad$ the change of wall thickness (m)

I current (A) $k \quad$ thermal conductivity $(\mathrm{W} / \mathrm{m} \mathrm{K})$

$m \quad$ mass $(\mathrm{kg})$

$P_{\text {in }} \quad$ input power (W)

$Q \quad$ heat transfer rate $(\mathrm{W})$

$t \quad$ time (s)

$T \quad$ temperature $\left({ }^{\circ} \mathrm{C}\right)$

$V \quad$ voltage (V)

$x \quad$ wall thickness (m)

Greek Symbols

$\Delta \quad$ delta

Subscripts

C cold side

$H \quad$ hot side

in input

$k \quad$ conduction

Abbreviation

COP coefficient of performance

DFHP double fan heat pipe

HSF heat sink fin-fan

\section{REFERENCES}

Abdul-Wahab, S.A.A., Elkamel, A., Al-Damkhi, A.M., Al-Habsi, I.A., Al-Rubai'ey', H.S., Al-Battashi, A.K., Al-Tamimi, A.R., Al-mamari, K.H., and Chutani, M.U., 2009, "Design and Experimental Investigation of the Portable Solar Thermoelectric Refrigerator", Renewable Energy, 34, 30-34. https://doi.org/10.1016/j.renene.2008.04.026

Ananta, H., Padang, Y.L., and Mirmanto, 2017, "Unjuk Kerja Kulkas Termoelektrik dengan Rangkaian Seri dan Paralel pada Beban Air 1500 ml”, Dinamika Teknik Mesin, 7(2), 80-86. https://doi.org/10.29303/dtm.v7i2.157.

Andersen, J.R., 1962, “TE Air Conditioner for Submarine”, Adv. Energy Convers, 2, 241-244.

Attey, G.S., 1998, "Enhanced thermoelectric refrigeration system COP through low thermal impedance liquid heat transfer system", 17th International Conference Thermoelectrics IEEE, 519-524. https://doi.org/10.1109/ICT.1998.740431

Cai, Y., Liu, D., Yang, J.J., Wang, Y., Zhao, F.Y., 2017, “Optimization of Thermoelectric Cooling System for Application in CPU Cooler", Energy Procedia, 105, 1644-1650. https://doi.org/10.1109/ICT.1998.740431

Cai, Y., Liu, D., Zhao, F.Y., and Tang, J.F., 2016, "Performance Analysis and Assessment of Thermoelectric Micro Cooler for Electronic Devices", Energy Conversion and Management, 124, 203-211. https://doi.org/10.1016/j.enconman.2016.07.011

Cengel, Y.A., 2003, Heat Transfer A Practical Approach, $2^{\text {nd }}$ ed., McGraw-Hill Companies, Inc., NY.

Chen, J., Yu, J., and Ma, M., 2015, “Theoretical Study on An Integrated Two-Staged Cascaded Thermoelectric Module Operating with Dual Power Sources", Energy Convers Manage, 98, 28-33. https://doi.org/10.1016/j.enconman.2015.03.090

Deng, X., 1992, "Thermoelectric Refrigeration and Applied Technology", Shanghai Jiaotong University Press.

Ghoshal, U., Ghoshal, S., McDowell, C., and Shi, L., 2002, "Enhanced TE Cooling at Cold Junction Interfaces", Applied Physics Letter, 80(16), 3006-3008.

https://doi.org/10.1063/1.1473233 
Gokcek, M., and Sahin, F., 2017, "Experimental Performance Investigation of Minichannel Water Cooled-Thermoelectric Refrigerator", Case Studies in Thermal Engineering, 10, 54-62. http://dx.doi.org/10.1016/i.csite.2017.03.004

Jugsujinda, S., Vora-ud, A., and Seeawan, T., 2011, "Analyzing of Thermoelectric Refrigerator Performance", Procedia Engineering, 8, 154-159.

https://doi.org/10.1016/i.proeng.2011.03.028

Lee, H.J., Anoop, G., Kim, C., Park, J.W., Choi, J., Kim, H., Kim, Y.J., Lee, E.J., Lee, S.G., Kim, Y.M., Lee, J.H., and Jo, J.Y., 2015, "Enhanced TE Performance of PEDOT: PSS/PANI-CSA Polymer Multilayer Structures", Energy \& Environmental Science, 0(1-3), 1-7. https://doi.org/10.1039/C5EE03063C

Lineykin, S., and Ben-Yaakov, S., 2007, "User-Friendly and Intuitive Graphical Approach to the Design of Thermoelectric Cooling Systems", Int. J. Refrigeration, 30, 798-804.

https://doi.org/10.1016/i.ijrefrig.2006.12.004

Lu, T., Zhou, J., Li, N., Yang, R., and Li, B., 2014, "Inhomogeneous thermal conductivity enhances thermoelectric cooling", AIP ADVANCES, 4.124501, 1-8.

http://dx.doi.org/10.1063/1.4903547

Manikandan, S., and Kaushik, S.C., 2015, "Energy and Exergy Analysis of an Annular Thermoelectric Cooler", Energy Convers Manage, 106, 804-814.

http://dx.doi.org/10.1016/j.enconman.2015.10.029

McNaughton, A.G., 1995, "Commercially Available Generators", in: D.M. Rowe (Ed.), CRC Handbook of TE, 1. CRC Press. Florida.

Mei, V.C., Chen, F.C., and Mathiprakasam, B., 1989, "Comparison of TE and Vapor Cycle Technologies for Groundwater Heat Pump Application”, ASME J, Solar Energy Engineering, 111, 353-360.

Min, G., and Rowe, D.M., 2006, "Experimental Evaluation of Prototype Thermoelectric Domestic-Refrigerators", Applied Energy, 83(2), 133152.

https://doi.org/10.1016/j.apenergy.2005.01.002

Rabari, R., Mahmud, S., and Dutta, A., 2015, "Effect of Thermal Conductivity on the Performance of Thermoelectric System Based on Effective Medium Theory", Int. J. Heat and Mass Transfer, 91, 190-204. http://dx.doi.org/10.1016/j.ijheatmasstransfer.2015.06.084
Rawat, M.K., Chattopadhyay, H., and Neogi, S., 2013, "A Review on Developments of Thermoelectric Refrigeration and Air Conditioning Systems: A Novel Potential Green Refrigeration and Air Conditioning Technology", Int. J. Engineering Technology and Advanced Engineering, 3, 362-367.

Reddy, B.V.K., Barry, M., Li, J., Chyu, M.K., 2013, "Enhancement of Thermoelectric Device Performance through Integrated Flow Channels", Frontiers in Heat and Mass Transfer, 4, 1-7. DOI: 10.5098/hmt.v4.2.3001. https://doi.org/10.5098/hmt.v4.2.3001

Reddy, N.J.M., 2016, “A Low Power, Eco-Friendly Multipurpose Thermoelectric Refrigerator", Front Energy, 10(1), 79-87. https://doi.org/10.1007/s11708-015-0380-8

Shen, L.M., Xiao, F., Chen, H.X., and Wang, S.W., 2013, "Investigation of A Novel Thermoelectric Radiant Air-Conditioning System", Energy and Buildings, 59, 123-132.

https://doi.org/10.1016/i.enbuild.2012.12.041

Su, Y., Lu, J., and Huang, B., 2018, "Free-standing planar thin-film thermoelectric micro refrigerators and the effects of thermal and electrical contact resistances", Int. J. Heat and Mass Transfer, 117, 436446.

https://doi.org/10.1016/j.ijheatmasstransfer.2017.10.023

Tan, G., and Zhao, D., 2015, "Study of a Thermoelectric Space Cooling System Integrated with Phase Change Material", Applied Thermal Engineering, 85, 187-198.

https://doi.org/10.1016/j.applthermaleng.2015.04.054

Totala, N.B., Desai, V.P., and Singh, R.K.N., 2014, "Study and Fabrication of Thermoelectric Air Cooling and Heating System", International Journal of Engineering Inventions, 4(2), 20-30.

Yang, J.J., Tan, S.J., and Wu, B.X., 1991, "Development and Effect Test of KWX-1 Portable Medical Refrigerator", Medical Equipment, 3, 1415 .

Yu, J., and Wang, B., 2009, "Enhancing the Maximum Coefficient of Performance of Thermoelectric Cooling Modules Using Internally Cascaded Thermoelectric Couples", Int. J. Refrigeration, 32, 32-39. https://doi.org/10.1016/j.ijrefrig.2008.08.006 